\title{
Safety of long-term denosumab therapy: results from the open label extension phase of two phase 3 studies in patients with metastatic breast and prostate cancer
}

\author{
Alison T. Stopeck ${ }^{1} \cdot$ Karim Fizazi $^{2} \cdot$ Jean-Jacques Body $^{3} \cdot$ Janet E. Brown $^{4,5} \cdot$ Michael Carducci $^{6}$. \\ Ingo Diel ${ }^{7}$ Yasuhiro Fujiwara ${ }^{8}$ - Miguel Martín ${ }^{9}$ - Alexander Paterson ${ }^{10}$ - Katia Tonkin ${ }^{11}$. \\ Neal Shore ${ }^{12}$ - Paul Sieber ${ }^{13} \cdot$ Frank Kueppers $^{14}$ • Lawrence Karsh $^{15}$ • Denise Yardley $^{16}$. \\ Huei Wang ${ }^{17}$ - Tapan Maniar $^{17}$ • Jorge Arellano ${ }^{17}$ • Ada Braun ${ }^{17}$
}

Received: 9 February 2015 / Accepted: 16 August 2015 /Published online: 3 September 2015

(C) The Author(s) 2015. This article is published with open access at Springerlink.com

\begin{abstract}
Purpose Zoledronic acid (ZA) or denosumab treatment reduces skeletal-related events; however, the safety of prolonged therapy has not been adequately studied. Here, we describe safety results of extended denosumab therapy in patients with bone metastases from the open-label extension phase of two phase 3 trials.

Methods Patients with metastatic breast or prostate cancer received subcutaneous denosumab $120 \mathrm{mg}$ Q4W or intravenous ZA 4 mg Q4W in a double-blinded fashion. Denosumab demonstrated superior efficacy in the blinded treatment phase; thus, patients were offered open-label denosumab for up to an additional 2 years.
\end{abstract}

Trial registration

These studies are registered with ClinicalTrials.gov with identifiers NCT00321620 and NCT00321464.

Alison T. Stopeck

Alison.Stopeck@stonybrookmedicine.edu

University of Arizona Cancer Center, Tucson, AZ, USA

2 Institut Gustave Roussy, University of Paris Sud, Villejuif, France

3 Centre Hospitalier Universitaire Brugmann, Université Libre de Bruxelles, Brussels, Belgium

4 Cancer Research UK Experimental Cancer Medicine Centres, St James's University Hospital, Leeds, UK

5 Weston Park Hospital, University of Sheffield, Sheffield, UK

6 Sidney Kimmel Comprehensive Cancer Center at Johns Hopkins, Baltimore, MD, USA

7 Center for Comprehensive Gynecology Clinic, Mannheim, Germany
Results Cumulative median (Q1, Q3) denosumab exposure was $19.1(9.2,32.2)$ months in the breast cancer trial $(n=1019)$ and $12.0(5.6,21.3)$ months in the prostate cancer trial $(n=942) ; 295$ patients received denosumab for $>3$ years. No new safety signals were identified during the open-label phase, or among patients who switched from ZA to denosumab. During the blinded treatment phase, exposureadjusted subject incidences of osteonecrosis of the jaw (ONJ) were $49(1.9 \%)$ and $31(1.2 \%)$ in the denosumab and ZA groups, respectively. In total, $32(6.9 \%)$ and 25 (5.5\%) new cases of ONJ (not adjusted for exposure) were reported for patients continuing and switching to denosumab,

8 National Cancer Center Hospital, Tokyo, Japan

9 Instituto de Investigación Sanitaria General Gregorio Marañón, Universidad Complutense, Madrid, Spain

10 Tom Baker Cancer Centre, Calgary, AB, Canada

11 Cross Cancer Institute, Edmonton, AB, Canada

12 Carolina Urologic Research Center, Myrtle Beach, SC, USA

13 Lancaster Urology, Lancaster, PA, USA

14 Urology Associates, Christchurch, New Zealand

15 The Urology Center of Colorado, Denver, CO, USA

16 Sarah Cannon Research Institute, Nashville, TN, USA

17 Amgen Inc., Thousand Oaks, CA, USA 
respectively. The incidences of hypocalcemia were 4.3 and $3.1 \%$, in patients continuing and switching to denosumab, respectively.

Conclusion These results describe the safety profile of denosumab after long-term exposure, or after switching to denosumab from ZA. No new safety signals were identified. Hypocalcemia rates were similar in the blinded treatment and open-label phases. ONJ rates increased with increasing exposure to antiresorptives, consistent with previous reports.

Keywords Bone metastases $\cdot$ Breast cancer $\cdot$ Denosumab . Osteonecrosis of the jaw $\cdot$ Prostate cancer $\cdot$ Zoledronic acid

\section{Introduction}

Patients with metastatic cancer are living longer and with improved quality of life [1]. Bone-targeted therapies for preventing skeletal-related events (SREs: fracture, spinal cord compression, and radiation or surgery to bone) are an integral component of care in the treatment of patients with bone metastases; and their use for longer durations seems warranted to prevent SREs, provided that the benefit is not outweighed by safety considerations.

Denosumab (XGEVA ${ }^{\circledR}$, Amgen Inc. Thousand Oaks, CA, USA), a fully human monoclonal antibody directed against receptor activator of nuclear factor kappa-B (RANK) ligand, has been approved for preventing SREs in patients with solid tumors based on results from three international double-blind, activecontrolled phase 3 trials comprising over 5700 patients [2]. Results from the two trials involving patients with breast and prostate cancers demonstrated superiority of denosumab compared with zoledronic acid (ZA) (Zometa ${ }^{\circledR}$, Novartis Pharmaceuticals Corporation, East Hanover, NJ, USA) for prevention of SREs. Consequently, patients were offered open-label denosumab for a period of up to 2 additional years once the results of the primary analysis were achieved. We now describe the safety results from long-term administration of denosumab in these two studies, including in patients previously treated with ZA.

\section{Methods}

\section{Patients}

Adults with breast or castration-resistant prostate cancer and radiographic evidence of at least one bone metastasis were enrolled as previously described [3, 4]. Both studies were conducted according to the Helsinki Declaration and the International Conference on Harmonization of Good Clinical Practice guidelines. Approvals from appropriate research ethics committees were obtained from each study center, and all patients provided written informed consent.

\section{Treatment}

In the double-blinded treatment phase, patients were randomized to receive subcutaneous (SC) denosumab (120 mg every 4 week (Q4W)) plus intravenous (IV) placebo or SC placebo plus IV ZA (4 mg Q4W) (Fig. 1). Following the positive results of the primary analysis, the patients were offered continued treatment with denosumab for up to 2 additional years during an open-label extension treatment phase. Patients initially randomized to denosumab during the blinded treatment phase (denosumab/denosumab group) continued to receive denosumab at $120 \mathrm{mg}$ Q4W. Patients initially randomized to ZA during the blinded phase and then switched to denosumab in the open-label phase (ZA/denosumab group) were treated with denosumab at $120 \mathrm{mg}$ Q4W starting 4 weeks from their last ZA dose. Patients who declined further therapy in the open-label extension phase, or who did not complete the blinded treatment phase, continued follow-up for survival every 12 weeks $(\mathrm{Q} 12 \mathrm{~W})$ for up to 2 years after their last dose in the blinded treatment phase.

\section{Safety outcomes}

Adverse events were monitored and potential osteonecrosis of the jaw (ONJ) events were adjudicated by an independent committee of dentists and oral surgeons [4]. ONJ rates were calculated as a ratio of the total number of adjudicated positive ONJ events and the total patient-years of follow-up, as patients were treated for different lengths of time. Eligible patients who enrolled in the open-label phase of the trials and received at least one dose of open-label denosumab were included in the safety analyses.

\section{Results}

Following the blinded portion of the trials, nearly $90 \%$ of eligible patients chose to continue or switch to denosumab therapy, including 667 breast cancer patients (325 and 342 initially randomized to denosumab and ZA, respectively) and 281 prostate cancer patients (153 and 128 randomized, respectively). Patient demographics (Table 1) were similar to those of the entire trial populations $[3,4]$.

\section{Drug exposure}

Among patients initially randomized to denosumab, cumulative median denosumab exposures (including blinded and open-label treatment phases) were slightly greater in the breast cancer study compared with the prostate cancer study (Table 2). Maximal exposures for patients in the denosumab/ denosumab group were up to 5 years in the breast cancer study and up to 5.6 years in the prostate cancer study. Prior to 


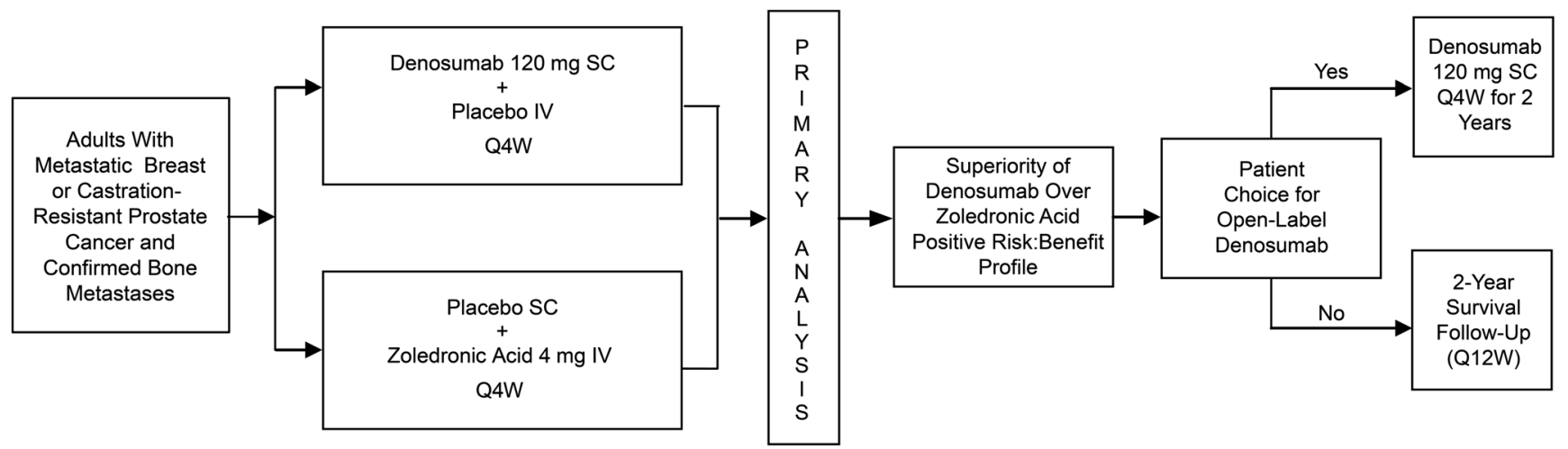

Fig. 1 Study design and treatment schema, $S C$ subcutaneous, $I V$ intravenous, $Q 4 W$ every 4 weeks

switching to open-label denosumab, the median (Q1, Q3) (range) exposures to ZA during the double-blinded treatment phase for all randomized patients were $18.4(9.1,24.9)$ (0.3-39.6) months in the breast cancer study and 10.2 $(4.9,17.8)(0-41.6)$ months in the prostate cancer study. Among patients who continued on the open-label phase, median (Q1, Q3) (range) ZA exposures were 19.6 (9.8, 25.0) (0-38.6) months and $11.2(5.7,19.4)(0-41.3)$ months, respectively. Across all phases of both studies, 295 patients received monthly denosumab for $\geqq 3$ years. In the breast cancer study, 216 and 76 patients received therapy for $\geqq 3$ and for $\geqq 4$ years, respectively; 79 and 29 patients received therapy for $\geqq 3$ and for $\geqq 4$ years, respectively, in the prostate cancer study.

\section{Safety}

Overall, 652 breast cancer patients (318 and 334 initially randomized to denosumab and ZA, respectively) and 265 prostate cancer patients (147 and 118 initially randomized to denosumab and ZA, respectively) received at least one dose of denosumab during the open-label treatment phase (Table 3). No new safety signals were observed during the open-label extension phase. No neutralizing anti-denosumab

Table 1 Selected patient characteristics at entry to open-label study phase

\begin{tabular}{|c|c|c|c|c|}
\hline \multirow[t]{2}{*}{ Characteristic } & \multicolumn{2}{|l|}{ Breast cancer study } & \multicolumn{2}{|c|}{ Prostate cancer study } \\
\hline & $\begin{array}{l}\text { Denosumab/ } \\
\text { Denosumab } \\
(n=325)\end{array}$ & $\begin{array}{l}\text { Zoledronic Acid/ } \\
\text { Densoumab } \\
(n=342)\end{array}$ & $\begin{array}{l}\text { Denosumab/ } \\
\text { Denosumab } \\
(n=153)\end{array}$ & $\begin{array}{l}\text { Zoledronic Acid/ } \\
\text { Denosumab } \\
(n=128)\end{array}$ \\
\hline Age (years) median [Q1, Q3] & $56.0[48.0,64.0]$ & $55.9[48.0,65.0]$ & $70.0[66.0,77.0]$ & $71.0[66.0,75.5]$ \\
\hline \multicolumn{5}{|l|}{ Age group, $n(\%)$} \\
\hline$\geq 65$ years & $74(22.8)$ & $86(25.1)$ & $121(79.1)$ & $98(76.6)$ \\
\hline$\geq 75$ years & $17(5.2)$ & $19(5.6)$ & $52(34.0)$ & $41(32.0)$ \\
\hline ECOG performance status, $n(\%)$ & $(n=299)$ & $(n=303)$ & $(n=139)$ & $(n=116)$ \\
\hline 0 or 1 & $288(96.3)$ & $287(94.7)$ & $124(89.2)$ & $102(87.9)$ \\
\hline$\geq 2$ & $11(3.7)$ & $16(5.3)$ & $15(10.8)$ & $14(12.1)$ \\
\hline BPI-SF pain severity, $n(\%)$ & $(n=325)$ & $(n=342)$ & $(n=153)$ & $(n=128)$ \\
\hline No pain $(0)$ & $71(21.8)$ & $62(18.1)$ & $38(24.8)$ & $28(21.9)$ \\
\hline Mild (1-4) & $143(44.0)$ & $158(46.2)$ & $66(43.1)$ & $49(38.3)$ \\
\hline Moderate (5-6) & $39(12.0)$ & $49(14.3)$ & $21(13.7)$ & $18(14.1)$ \\
\hline Severe $(7-10)$ & $43(13.2)$ & $46(13.5)$ & $17(11.1)$ & $19(14.8)$ \\
\hline Missing & $5(1.5)$ & $4(1.2)$ & $0(0.0)$ & $1(0.8)$ \\
\hline Creatinine clearance $(\mathrm{mL} / \mathrm{min}), n(\%)$ & $(n=318)$ & $(n=334)$ & $(n=147)$ & $(n=118)$ \\
\hline 15 to $<30$ & $1(0.3)$ & $0(0.0)$ & $3(2.0)$ & $5(4.2)$ \\
\hline 30 to $<60$ & $31(9.7)$ & $48(14.4)$ & $28(19.0)$ & $24(20.3)$ \\
\hline 60 to $>90$ & $103(32.4)$ & $101(30.2)$ & $52(35.4)$ & $43(36.4)$ \\
\hline$\geq 90$ & $168(52.8)$ & $162(48.5)$ & $59(40.1)$ & $39(33.1)$ \\
\hline Missing & $15(4.7)$ & $23(6.9)$ & $5(3.4)$ & $7(5.9)$ \\
\hline
\end{tabular}

Q1, Q3 first and third quartiles, ECOG Eastern Cooperative Oncology Group, BPI-SF Brief Pain Inventory-Short Form 
Table 2 Cumulative exposure to denosumab in the open-label phase and over the entire study period

\begin{tabular}{|c|c|c|c|c|}
\hline \multirow[t]{2}{*}{ Median (Q1, Q3) [range] exposure, months } & \multicolumn{2}{|c|}{ Denosumab/Denosumab } & \multicolumn{2}{|c|}{ Zoledronic Acid/Denosumab ${ }^{\mathrm{a}}$} \\
\hline & $\begin{array}{l}\text { Breast cancer study } \\
(n=1019)\end{array}$ & $\begin{array}{l}\text { Prostate cancer } \\
\text { study }(n=942)\end{array}$ & $\begin{array}{l}\text { Breast cancer study } \\
(n=1019)\end{array}$ & $\begin{array}{l}\text { Prostate cancer study } \\
(n=942)\end{array}$ \\
\hline $\begin{array}{l}\text { Open-label extension phase }{ }^{\mathrm{b}} \\
\text { Full study (double-blinded and } \\
\text { open label phases) }{ }^{\mathrm{c}}\end{array}$ & $\begin{array}{l}17.6(8.3,23.0) \\
{[0-23.7]} \\
(n=318) \\
19.1(9.2,32.2) \\
{[0.1-59.8]}\end{array}$ & $\begin{array}{l}12.0(5.3,22.1) \\
{[0.1-23.3]} \\
(n=147) \\
12.0(5.6,21.3) \\
{[0.1-67.2]}\end{array}$ & $\begin{array}{l}16.3(7.4,22.8) \\
{[0.5-23.3]} \\
(n=334) \\
\text { Open-label phase only }{ }^{\mathrm{a}}\end{array}$ & $\begin{array}{l}12.0(5.5,20.5) \\
{[0.4-23.3]} \\
(n=118) \\
\text { Open-label phase only }{ }^{\mathrm{a}}\end{array}$ \\
\hline
\end{tabular}

Q1, Q3 first and third quartiles

${ }^{a}$ Patients received denosumab in the open-label phase only

${ }^{\mathrm{b}}$ Denosumab exposure in the open-label extension treatment phase only

${ }^{\mathrm{c}}$ Cumulative denosumab exposure in the double-blinded and open-label extension phases for all randomized patients

antibodies were detected. Rates of adverse events and serious adverse events were similar to those seen during the studies' blinded treatment phases. Adverse events were generally balanced between treatment groups independent of whether patients were initially randomized to denosumab or ZA during the blinded phase of the study (Table 3).

In the blinded phase, adverse events of infection were reported by similar percentages of patients in both treatment groups [3, 4]. Adverse events of infection overall occurred in approximately $40 \%$ of patients during the open-label phase (Table 3). The most common infections observed were nasopharyngitis, urinary tract infections, and influenza in the breast cancer study and urinary tract infections, nasopharyngitis, and pneumonia in the prostate cancer study. Overall, the incidences of infectious events were generally similar to those observed in the blinded treatment phases for each study.

During the blinded treatment phase, the combined incidence, adjusted for years of patient follow-up, of positively adjudicated ONJ for both trials was $49(1.9 \%)$ in the denosumab group and 31 (1.2\%) in the ZA group. The patient incidence of ONJ during the open-label extension phase, not adjusted for years of patient follow-up, was $32(6.9 \%)$ in the denosumab/denosumab group and $25(5.5 \%)$ in the ZA/ denosumab group. Incidence by study is shown in Table 3 . Most of the events of ONJ in the open-label phases were mild or moderate in severity and were treated conservatively. A history of tooth extraction, poor oral hygiene, and/or use of a dental appliance was documented in $53(93 \%)$ patients who developed ONJ; tooth extractions accounted for 26 (49 \%) of these cases. For patients initially randomized to denosumab, the median $(\mathrm{Q} 1, \mathrm{Q} 3)$ time from blinded treatment initiation to the onset of ONJ was $20.6(14.0,30.5)$ months overall for the full study period in both studies combined. In the breast cancer study, $37 \%$ received conservative treatment (mouth rinses and antibiotics) and $63 \%$ had limited surgical treatment (i.e., sequestrectomy, debridement, and curettage). In the prostate cancer study, $47 \%$ of patients had conservative management, and $52 \%$ had limited surgical treatments; one patient required a partial maxillary resection.

Among all patients who developed $\mathrm{ONJ}$ across blinded and open-label extension phases, 35/83 (42\%) patients in the breast cancer study and 15/57 (26\%) in the prostate cancer study had resolution of ONJ, defined as complete mucosal coverage of exposed bone. The median (Q1, Q3) time to ONJ resolution was $7.9(3.4,13.4)$ months in the denosumab/denosumab and $9.2(8.0,16.7)$ months in the $\mathrm{ZA} /$ denosumab groups for the breast cancer study, and 10.0 $(5.3,14.9)$ months and $13.0(6.5,23.2)$ months, respectively, for the prostate cancer study. Eleven (13\%) and $22(40 \%)$ patients in the breast and prostate cancer studies, respectively, died before ONJ resolution.

For patients in the breast cancer study who received denosumab throughout, the cumulative patient-year adjusted incidence of ONJ, including both the blinded and open-label extension phases of the trial, was $2.5 \%$ for a median (Q1, Q3) (range) of $19.1(9.2,32.2)$ (0.1 to $59.8)$ months. A similar incidence of ONJ was noted in patients who received denosumab throughout the prostate cancer trial, with a cumulative incidence of $2.8 \%$ with a median (Q1, Q3) (range) exposure to denosumab of $12.0(5.6,21.3)(0.1-67.2)$ months.

Overall, for both studies, 18 patients $(1.1 \%$ per 100 patient-years, comprising 1602 total patient-years of follow-up) and 11 patients $(0.7 \%$ per 100 patient-years, comprising 1570 total patient-years follow-up) developed confirmed ONJ during the first year of denosumab or ZA treatment, respectively. ONJ incidence rates observed in the blinded treatment phases for the individual trials are shown by time of onset in Fig. 2. Rates were not significantly different between ZA and denosumab groups for the first or subsequent years of treatment, although numbers were numerically higher for denosumab at all time points. During subsequent years 
Table 3 Adverse events during the open-label treatment phase

\begin{tabular}{|c|c|c|c|c|}
\hline \multirow[t]{2}{*}{ Event, $n(\%)$} & \multicolumn{2}{|l|}{ Breast cancer study } & \multicolumn{2}{|l|}{ Prostate cancer study } \\
\hline & $\begin{array}{l}\text { Denosumab/Denosumab } \\
(N=318)^{\mathrm{a}}\end{array}$ & $\begin{array}{l}\text { Zoledronic Acid/Denosumab } \\
(N=334)^{\mathrm{a}}\end{array}$ & $\begin{array}{l}\text { Denosumab/Denosumab } \\
(N=147)^{\mathrm{a}}\end{array}$ & $\begin{array}{l}\text { Zoledronic Acid/ } \\
\text { Denosumab }(N=118)^{a}\end{array}$ \\
\hline All adverse events & $283(89.0)$ & $303(90.7)$ & $138(93.9)$ & $105(89.0)$ \\
\hline Serious adverse events & $126(39.6)$ & $133(39.8)$ & $78(53.1)$ & $63(53.4)$ \\
\hline \multicolumn{5}{|l|}{ Most common adverse events } \\
\hline Nausea & $72(22.6)$ & $77(23.1)$ & $20(13.6)$ & $16(13.6)$ \\
\hline Anemia & $3(16.7)$ & $50(15.0)$ & $34(23.1)$ & $26(22.0)$ \\
\hline Fatigue & $70(22.0)$ & $74(22.2)$ & $23(15.6)$ & $15(12.7)$ \\
\hline Back pain & $66(20.8)$ & $56(16.8)$ & $29(19.7)$ & $19(16.1)$ \\
\hline Asthenia & $40(12.6)$ & $48(14.4)$ & $29(19.7)$ & $11(9.3)$ \\
\hline Arthralgia & $57(17.9)$ & $61(18.3)$ & $25(17.0)$ & $17(14.4)$ \\
\hline Adverse events of infection ${ }^{\mathrm{b}}$ & $135(42.5)$ & $135(40.4)$ & $58(39.5)$ & $33(28.0)$ \\
\hline Osteonecrosis of the jaw (ONJ) ${ }^{\mathrm{c}, \mathrm{d}}$ & $20(6.3)$ & $18(5.4)$ & $12(8.2)$ & $7(5.9)$ \\
\hline CTCAE, $v 3$ grade 3 & $2(0.6)$ & $6(1.8)$ & $3(2.0)$ & $1(0.8)$ \\
\hline CTCAE, $v 3$ grade 4 & $0(0.0)$ & $1(0.3)$ & $0(0.0)$ & $1(0.8)$ \\
\hline Adverse events of new primary malignancy & $2(0.6)^{\mathrm{f}}$ & $1(0.3)^{\mathrm{g}}$ & $1(0.7)^{\mathrm{h}}$ & $0(0.0)$ \\
\hline Adverse events of hypocalcemia ${ }^{\mathrm{i}}$ & $12(3.8)$ & $9(2.7)$ & $8(5.4)$ & $5(4.2)$ \\
\hline Serious & $3(0.9)$ & $0(0.0)$ & $1(0.7)$ & $1(0.8)$ \\
\hline
\end{tabular}

CTCAE Common Terminology Criteria for Adverse Events; version 3

${ }^{a}$ Number of patients who received at least one dose of open-label denosumab

${ }^{\mathrm{b}}$ System organ class: Infections and Infestations, Medical Dictionary for Regulatory Activities version 14.0 (breast cancer study), 14.1 (prostate cancer study)

${ }^{\mathrm{c}}$ Positively adjudicated by blinded committee of experts. There were no grade 5 ONJ events

${ }^{\mathrm{d}}$ Rates not adjusted for patient-years of investigational product exposure and patient follow-up

${ }^{\mathrm{e}}$ No events were considered by the investigator to be related to denosumab treatment

${ }^{f}$ Renal cell cancer, squamous cell carcinoma of the skin

${ }^{\mathrm{g}}$ Germ cell cancer

${ }^{\text {h }}$ Bladder cancer

${ }^{\mathrm{i}}$ Includes the preferred terms hypocalcemia and blood calcium decreased

that included open-label treatment, 31 patients $(4.1 \%$ per 100 patient-years, comprising 1616 patient-years of follow-up) in the denosumab/denosumab group developed confirmed ONJ.

During the open-label extension phase of the breast and prostate cancer trials, adverse events of hypocalcemia were observed at similar frequency comparing those who continued with denosumab therapy (20 (4.3\%)) versus those who switched from $\mathrm{ZA}$ to denosumab treatment $(14(3.1 \%))$. Overall, hypocalcemia rates during the open-label phase were similar to slightly lower compared with those observed in the blinded treatment phase. Six patients in the denosumab/denosumab group and five patients in the $\mathrm{ZA} /$ denosumab group had adverse events of hypocalcemia requiring IV calcium therapy; these events were considered serious in four and one patients, respectively (Table 3). Among these, one patient in each group had a baseline creatinine clearance $<60 \mathrm{~mL} / \mathrm{min}$; two patients in the $\mathrm{ZA} /$ denosumab group and one in the denosumab/denosumab group did not report oral vitamin D or calcium supplementation, respectively. In the breast cancer study, there was 1 (0.3 \%) Common Terminology Criteria for Adverse Events (CTCAE; version 3) grade 4 hypocalcemia event reported for each group, with no grade 3 events. In the prostate cancer study, there were $3(2.0 \%)$ and 2 (1.7\%) CTCAE grade 3 hypocalcemia events reported for the groups initially receiving denosumab and ZA, respectively, and $1(0.7)$ grade 4 event reported for the denosumab group. No patients had symptoms associated with severe hypocalcemia, nor were there any fatal adverse events of hypocalcemia. Overall, the incidence of hypocalcemia did not increase with increased exposure to denosumab. The risk of hypocalcemia during the open-label phase was not increased in patients who switched from ZA to denosumab, or in those who had impaired renal function.

\section{Overall survival}

Overall survival throughout the duration of the study was similar between treatment groups for both trials (Fig. 3a, 3b). 


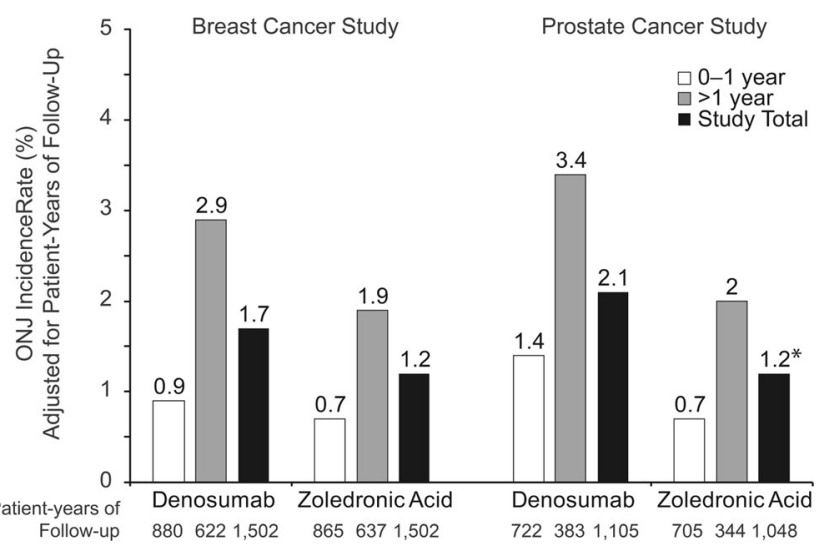

Fig. 2 ONJ rates for the blinded treatment phases of the breast cancer and prostate cancer trials during the first year of treatment, subsequent years of treatment, and blinded treatment overall. Incidence rates are adjusted for patient-years of follow-up to reflect different lengths of time on study, and expressed per 100 patient-years of follow-up, calculated as a ratio of the total number of adjudicated positive ONJ events and the total subjectyears of follow-up through either the end-of-study date or the blinded treatment phase cutoff date. $O N J$ osteonecrosis of the jaw

* One additional patient in the zoledronic acid/denosumab group developed ONJ after the end-of-study date

\section{Discussion}

In patients with metastatic cancers, SREs impair healthrelated quality of life, decreasing functional capabilities and increasing pain and opioid use [5]. With more efficacious and targeted antitumor therapies, further improvements in overall survival are expected. Because SRE risk increases with progression of metastatic disease $[6,7]$, maintaining quality of life by preventing complications of bone metastases, including SREs and hypercalcemia, remains a priority.

The long-term safety of IV bisphosphonates has not been adequately studied in controlled trials, and concerns regarding long-term complications including renal toxicity, ONJ, and atypical femoral fractures remain a primary rationale for the current practice of withholding therapy or implementing a less intensive schedule of therapy after $1-2$ years $[8,9]$. Recent trials designed to determine the optimal bisphosphonate dosing based on serum or urinary markers of bone turnover have experienced poor accrual and limitations in study design. This has led to inconclusive results, with no clear support for a decrease in toxicities or maintained efficacy for preventing SREs with less frequent dosing schedules (Q12W [10], or Q9W or Q16W [11]) or total number of doses administered $[12,13]$. The recently presented OPTIMIZE-2 trial also compared Q12W with Q4W ZA therapy in patients with metastatic breast cancer and bone metastases who had previously received at least 1 year of monthly ZA [14]. Non-inferiority in the 1-year SRE rate was reached in the study $(95 \%$ CI: -7.5 to $9.8 \%$ ); however, study accrual was amended secondary to poor accrual, and only 403 patients were ultimately randomized and followed for 1 year [14]. Additional trials including the CALGB 70604 trial [15] comparing Q12W with Q4W dosing will provide additional data on the risk:benefit profile associated with less intensive bisphosphonate schedules.

Denosumab is a fully human monoclonal antibody with a half-life of several weeks [16] and is not eliminated via the kidneys compared with bisphosphonates, which are primarily eliminated renally, bind to hydroxyapatite, and may remain
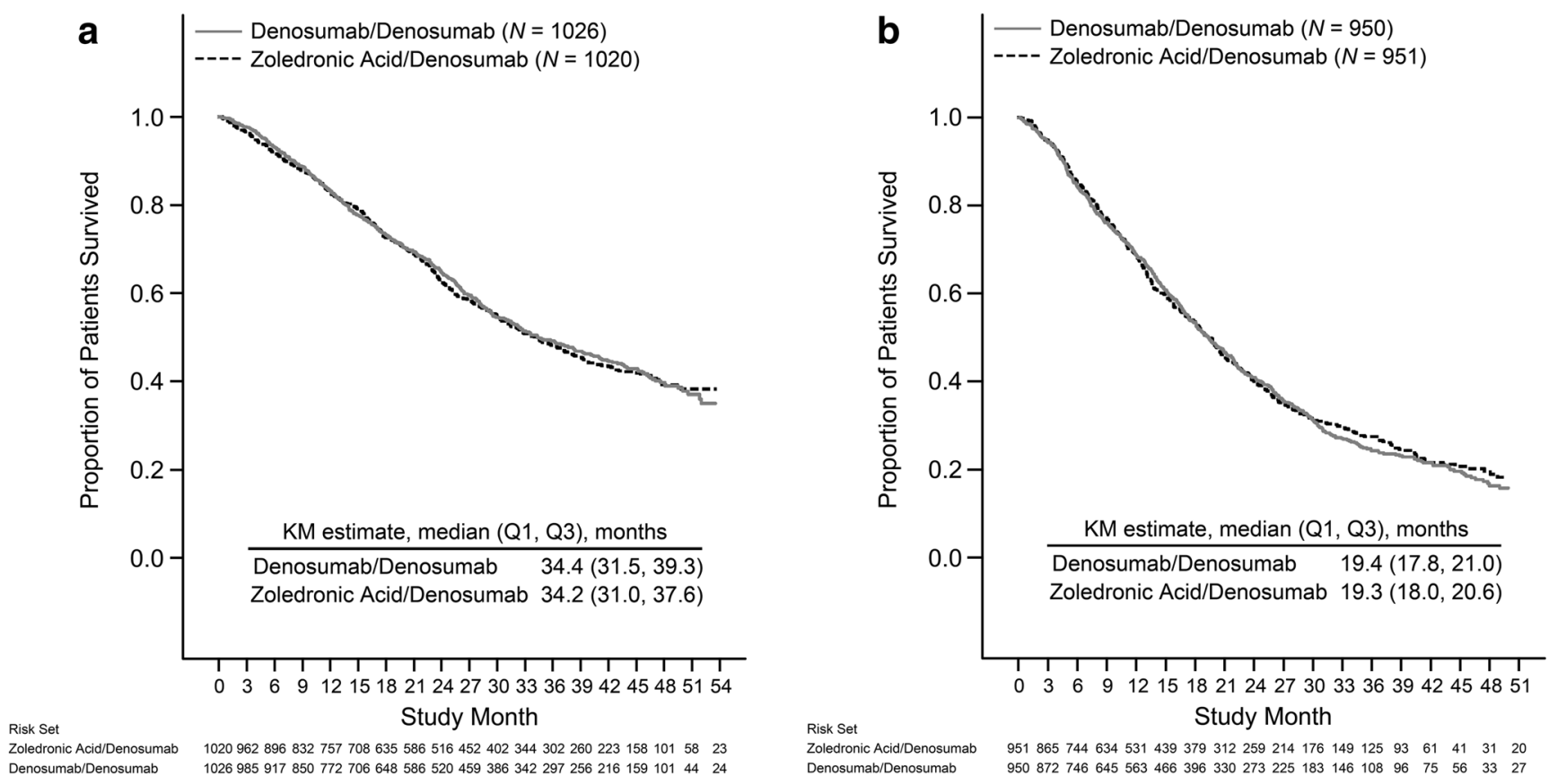

Fig. 3 Kaplan-Meier estimates of overall survival for the duration of the breast (a) and prostate (b) cancer studies. KM Kaplan-Meier, Q1, Q3 
sequestered in bones for many years [17]. Beyond the previously described differences in clinical efficacy [2], denosumab's mechanism of action and its more rapid reversibility may make the antibody a better option especially for patients susceptible to bisphosphonaterelated complications, or those with compromised renal function. As with previous reports for patients who switched from ZA treatment to denosumab treatment [18], there were no apparent safety issues associated with the change in treatment.

Additionally, the prolonged use of denosumab in these patients for a median 19.1 months of Q4W therapy was associated with no newly identified safety signals, no unexpected toxicity, and no requirement for dose reductions or changes in the dosing schedule. No events of atypical femoral fractures were noted in the three pivotal phase 3 denosumab trials in patients with bone metastases from solid tumors. However, this complication has been reported rarely in patients receiving oral or IV bisphosphonates [19] and more recently with denosumab at $60 \mathrm{mg}$ every 6 months (Prolia ${ }^{\mathbb{B}}$ ) [20] for osteoporosis, as well as in one case following long-term dosing with denosumab $120 \mathrm{mg}$ Q4W $\left(\mathrm{XGEVA}^{\circledR}\right)$ in an unapproved indication [21]. Thus, patients should be informed regarding this potential risk with long-term bone-targeted therapy.

Adverse events of ONJ and hypocalcemia were also observed in the open-label treatment phase. The majority of ONJ cases were associated with known risk factors involving invasive dental procedures and poor oral hygiene [22]; and the incidence rate increased with the duration of anti-resorptive therapy $[23,24]$. However, it should be noted that in the absence of bone-targeted therapy, SRE rates also increase over time and occur at a rate that far exceeds ONJ [25, 26]. Hypocalcemia was similar in incidence between treatment groups, manageable with appropriate therapy, and occurred at rates similar to those reported in the double-blinded phases of the studies. Few clinical trials have assessed the safety of potent anti-resorptive agents in advanced cancer patients beyond 2 years. A retrospective study in women with metastatic breast cancer who had received ZA or pamidronate for at least 24 months found that the rate of ONJ in these patients was $3.8 \%$ [27]. This rate is similar to the $2.5 \%$ rate reported for breast cancer patients in our study who received denosumab in both the blinded and open label treatment phases. The results presented in this manuscript are important for confirming the need to vigilantly follow patients for these known side effects of bone-targeted therapies, even after prolonged availability and administration of these agents. Patients should continue to be counseled on the importance of dental hygiene and preventive dentistry and adherence to calcium and vitamin D supplements while receiving bone-targeted treatment, particularly those with severe renal impairment
[28]. Healthcare providers should also ensure that patients receiving bone-targeted therapy are aware of the symptoms associated with hypocalcemia, including muscle stiffness, twitching, spasms, or cramps [21], and should monitor these patients, including cardiac monitoring in patients with severe hypocalcemia.

In conclusion, data from the open-label extension phase of two pivotal trials in metastatic breast and prostate cancer, respectively, confirm the known safety profile of denosumab with long-term administration for a median 19.1 months (up to 5 years) in metastatic breast cancer and a median 12.0 months (up to 5.6 years) in metastatic prostate cancer. Additionally, there were no new safety signals among patients who were switched to denosumab therapy after continuous ZA treatment, suggesting that changing from an IV bisphosphonate to denosumab is a valid treatment strategy where clinically indicated for patients with advanced breast and prostate cancers [29].

Acknowledgments This work was supported by Amgen Inc. Geoff Smith, $\mathrm{PhD}$, provided medical writing support on behalf of Amgen Inc.

Conflict of interest Alison T. Stopeck served as a consultant for Amgen Inc., Pfizer, Bayer, Genentech, and Clovis Pharmaceuticals. She received research funding from Amgen Inc., Novartis, Peregrine, Puma, and Bayer. Karim Fizazi received remuneration and served as a consultant for Amgen Inc. Jean-Jacques Body worked as a consultant for Amgen Inc. and Bayer. Janet E. Brown worked as a consultant for Amgen Inc., Novartis, and Bristol Myers Squibb and received remuneration from these companies. Michael Carducci served as a consultant for Amgen Inc. Ingo Diel received remuneration from Amgen Inc., Medtronic, TEVA, and GSK, and served as a consultant for Amgen Inc., Medtronic, and TEVA. Yasuhiro Fujiwara received research funding from Kyowa Hakko Kirin Co Ltd., GlaxoSmithKline KK, Sanofi Aventis KK, Daiichi Sankyo Co Ltd., Taiho Pharmaceutical Co Ltd., Takeda Pharmaceutical Co Ltd., Takeda Bio Development Center Ltd., Chugai Pharmaceutical Co Ltd., Nihon Kayaku Co Ltd., Nippon Boehringer Ingelheim Co Ltd., Novartis Pharma KK, Pfizer Japan, Bristol Myers KK, Janssen Pharmaceutical KK, and Kissei Pharmaceutical Co Ltd. He received lecture fees from AstraZeneca KK, Bristol Myers KK, Chugai Pharmaceutical Co Ltd., Daiichi Sankyo Co Ltd., NEC Corporation, Novartis Pharma KK, Sanofi Aventis KK, and Taiho Pharmaceutical Co Ltd. He served on scientific advisory boards at Chugai Pharmaceutical Co Ltd., MedImmune, and Eli Lilly Japan. Miguel Martín served as a consultant for Amgen Inc., Novartis, and Roche Diagnostics. His received research funding from Amgen Inc. Alexander Paterson served as a consultant and received honoraria from Amgen Inc. and Novartis. Neal Shore served as a consultant for Astellas, Bayer, Dendreon, Ferring, Janssen, Medivation, Millennium, and Sanofi. Paul Sieber received remuneration (for Speaker's bureau) from Amgen Inc. Lawrence Karsh served as a consultant for Amgen Inc., Astellas, Medivation, BNiT, Myriad, Bayer, Tolmar, Genomic Health, Dendreon, and Janssen, and hold stock in Swan Valley Medical. His received research funding from Amgen, Astellas, Medivation, BNiT, Jannsen, Dendreon, Pfizer, Takeda, Orion, Auxillium, Argos, MDX Health, and Genomic Health. Denise Yardley, Frank Kueppers, and Katia Tonkin have no stated conflicts. Huei Wang, Tapan Maniar, and Jorge Arellano are employees and stockholders of Amgen Inc. Ada Braun is a former employee and stockholder Amgen Inc. The authors state that they have full control of all primary data, and they agree to allow the journal to review their data if requested. 
Open Access This article is distributed under the terms of the Creative Commons Attribution-NonCommercial 4.0 International License (http:// creativecommons.org/licenses/by-nc/4.0/), which permits any noncommercial use, distribution, and reproduction in any medium, provided you give appropriate credit to the original author(s) and the source, provide a link to the Creative Commons license, and indicate if changes were made.

\section{References}

1. Kris MG, Benowitz SI, Adams S, Diller L, Ganz P, Kahlenberg MS, Le QT, Markman M, Masters GA, Newman L, Obel JC, Seidman AD, Smith SM, Vogelzang N, Petrelli NJ (2010) Clinical cancer advances 2010: annual report on progress against cancer from the American society of clinical oncology. J Clin Oncol 28:5327-5347

2. Lipton A, Fizazi K, Stopeck AT, Henry DH, Brown JE, Yardley DA, Richardson GE, Siena S, Maroto P, Clemens M, Bilynskyy B, Charu V, Beuzeboc P, Rader M, Viniegra M, Saad F, Ke C, Braun A, Jun S (2012) Superiority of denosumab to zoledronic acid for prevention of skeletalrelated events: a combined analysis of 3 pivotal, randomised, phase 3 trials. Eur J Cancer 48:3082-3092

3. Fizazi K, Carducci M, Smith M, Damiao R, Brown J, Karsh L, Milecki P, Shore N, Rader M, Wang H, Jiang Q, Tadros S, Dansey R, Goessl C (2011) Denosumab versus zoledronic acid for treatment of bone metastases in men with castration-resistant prostate cancer: a randomised, double-blind study. Lancet 377 : 813-822

4. Stopeck AT, Lipton A, Body JJ, Steger GG, Tonkin K, de Boer RH, Lichinitser M, Fujiwara Y, Yardley DA, Viniegra M, Fan M, Jiang Q, Dansey R, Jun S, Braun A (2010) Denosumab compared with zoledronic acid for the treatment of bone metastases in patients with advanced breast cancer: a randomized, double-blind study. J Clin Oncol 28:5132-5139

5. Fallowfield L, Cleeland CS, Body JJ, Stopeck A, von Moos R, Patrick DL, Clemons M, Tonkin K, Masuda N, Lipton A, de Boer R, Salvagni S, Oliveira CT, Ying W, Braun A, Cong Z (2011) Pain severity and analgesic use associated with skeletal-related events in patients with advanced breast cancer and bone metastases. Cancer Res 71(Suppl 3):Abstract P4-13-01

6. Coleman RE (2001) Metastatic bone disease: clinical features, pathophysiology and treatment strategies. Cancer Treat Rev 27:165-176

7. Tchekmedyian NS, Chen YM, Saad F (2010) Disease progression increases the risk of skeletal-related events in patients with bone metastases from castration-resistant prostate cancer, lung cancer, or other solid tumors. Cancer Investig 28:849-855

8. Chang ST, Tenforde AS, Grimsrud CD, O’Ryan FS, Gonzalez JR, Baer DM, Chandra M, Lo JC (2012) Atypical femur fractures among breast cancer and multiple myeloma patients receiving intravenous bisphosphonate therapy. Bone 51:524-527

9. Dunstan CR, Felsenberg D, Seibel MJ (2007) Therapy insight: the risks and benefits of bisphosphonates for the treatment of tumorinduced bone disease. Nat Clin Pract Oncol 4:42-55

10. Amadori D, Aglietta M, Alessi B, Gianni L, Ibrahim T, Farina G, Gaion F, Bertoldo F, Santini D, Rondena R, Bogani P, Ripamonti CI (2013) Efficacy and safety of 12weekly versus 4-weekly zoledronic acid for prolonged treatment of patients with bone metastases from breast cancer (ZOOM): a phase 3, open-label, randomised, non-inferiority trial. Lancet Oncol 14:663-670
11. Coleman RE, Wright J, Houston S, Agrawal R, Purohit OP-K, Hayward L, Simmonds P, Waterhouse A, Marshall H, BISMARK Investigators (2012) Randomized trial of marker-directed versus standard schedule zoledronic acid for bone metastases from breast cancer. J Clin Oncol 30(Suppl):Abstract 511

12. Hoff AO, Toth BB, Altundag K, Johnson MM, Warneke CL, $\mathrm{Hu}$ M, Nooka A, Sayegh G, Guarneri V, Desrouleaux K, Cui J, Adamus A, Gagel RF, Hortobagyi GN (2008) Frequency and risk factors associated with osteonecrosis of the jaw in cancer patients treated with intravenous bisphosphonates. J Bone Miner Res 23:826-836

13. Ruggiero SL, Dodson TB, Fantasia J, Goodday R, Aghaloo T, Bhoomi M, O'Ryan F (2014) American association of oral and maxillofacial surgeons position paper on medication-related osteonecrosis of the jaw-2014 update. J Oral Maxillofac Surg 72:1938-1956

14. Hortobagyi G, Lipton A, Chew H, Gradishar W, Sauter N, Mohanlal R, Zheng M, McGrain B, Van Poznak C (2014) Efficacy and safety of continued zoledronic acid every 4 weeks versus every 12 weeks in women with bone metastases from breast cancer: results of the optimize-2 trial. J Clin Oncol 32(Suppl): Abstract LBA9500

15. Cancer and Leukemia Group B (2012) Zoledronic acid in treating patients with metastatic breast cancer, metastatic prostate cancer, or multiple myeloma with bone involvement. ClinicalTrials.gov. http://clinicaltrials.gov/show/NCT00869206. Accessed 01 December 2014

16. Doshi S, Sutjandra L, Zheng J, Sohn W, Peterson M, Jang G, Chow AT, Perez-Ruixo JJ (2012) Denosumab dose selection for patients with bone metastases from solid tumors. Clin Cancer Res 18:2648-2657

17. Russell RG, Watts NB, Ebetino FH, Rogers MJ (2008) Mechanisms of action of bisphosphonates: similarities and differences and their potential influence on clinical efficacy. Osteoporos Int 19:733-759

18. Fizazi K, Lipton A, Mariette X, Body JJ, Rahim Y, Gralow JR, Gao G, Wu L, Sohn W, Jun S (2009) Randomized phase II trial of denosumab in patients with bone metastases from prostate cancer, breast cancer, or other neoplasms after intravenous bisphosphonates. J Clin Oncol 27:1564-1571

19. Gedmintas L, Solomon D, Kim S (2013) Bisphosphonates and risk of subtrochanteric, femoral shaft, and atypical femur fracture: a systematic review and meta-analysis. J Bone Miner Res 28: 1729-1737

20. Paparodis R, Buehring B, Pelley E, Binkley N (2013) A case of an unusual subtrochanteric fracture in a patient receiving denosumab. Endocr Pract 19:e64-e68

21. $\mathrm{XGEVA}^{\circledR}$ (denosumab) US Package Insert (2014) Amgen Inc. Thousand Oaks, CA

22. Saad F, Brown JE, Van Poznak C, Ibrahim T, Stemmer SM, Stopeck AT, Diel IJ, Takahashi S, Shore N, Henry DH, Barrios CH, Facon T, Senecal F, Fizazi K, Zhou L, Daniels A, Carriere P, Dansey R (2012) Incidence, risk factors, and outcomes of osteonecrosis of the jaw: integrated analysis from three blinded active-controlled phase III trials in cancer patients with bone metastases. Ann Oncol 23:1341-1347

23. Smith MR, Saad F, Coleman R, Shore N, Fizazi K, Tombal B, Miller K, Sieber P, Karsh L, Damiao R, Tammela TL, Egerdie B, Van Poppel H, Chin J, Morote J, Gomez-Veiga F, Borkowski T, Ye Z, Kupic A, Dansey R, Goessl C (2012) Denosumab and bonemetastasis-free survival in men with castration-resistant prostate cancer: results of a phase 3 , randomised, placebo-controlled trial. Lancet 379:39-46

24. Smith MR, Saad F, Oudard S, Shore N, Fizazi K, Sieber P, Tombal B, Damiao R, Marx G, Miller K, Van Veldhuizen P, Morote J, Ye Z, Dansey R, Goessl C (2013) Denosumab and 
bone metastasis-free survival in men with nonmetastatic castration-resistant prostate cancer: exploratory analyses by baseline prostate-specific antigen doubling time. J Clin Oncol 31:3800-3806

25. Rosen LS, Gordon D, Tchekmedyian NS, Yanagihara R, Hirsh V, Krzakowski M, Pawlicki M, De Souza P, Zheng M, Urbanowitz G, Reitsma D, Seaman J (2004) Long-term efficacy and safety of zoledronic acid in the treatment of skeletal metastases in patients with nonsmall cell lung carcinoma and other solid tumors: a randomized, phase III, double-blind, placebocontrolled trial. Cancer 100:2613-2621

26. Saad F, Gleason DM, Murray R, Tchekmedyian S, Venner P, Lacombe L, Chin JL, Vinholes JJ, Goas JA, Zheng M, Zoledronic Acid Prostate Cancer Study Group (2004) Long-term efficacy of zoledronic acid for the prevention of skeletal complications in patients with metastatic hormone-refractory prostate cancer. J Natl Cancer Inst 96:879-882

27. Brufsky AM, Sereika SM, Mathew A, Tomifumi O, Singh V, Rosenzweig M (2013) Long-term treatment with intravenous bisphosphonates in metastatic breast cancer: a retrospective study. Breast J 19:504-511

28. Block GA, Bone HG, Fang L, Lee E, Padhi D (2012) A single-dose study of denosumab in patients with various degrees of renal impairment. J Bone Miner Res 27:1471-1479

29. Body JJ, Lipton A, Gralow J, Steger GG, Gao G, Yeh H, Fizazi K (2010) Effects of denosumab in patients with bone metastases with and without previous bisphosphonate exposure. J Bone Miner Res $25: 440-446$ 